\title{
OPEN The generation of marine litter in Mediterranean island beaches as an effect of tourism and its mitigation
}

\begin{abstract}
Michaël Grelaud ${ }^{1 \bowtie}$ \& Patrizia Ziveri ${ }^{1,2}$
The Mediterranean Sea and its coastal systems are threatened by intense anthropogenic pressures including rapid accumulation of marine litter by diverse human activities. The region, which is the world's leading touristic destination, has to face a seasonal increase of waste generation due to the seasonal influx of visitors. The beaches, extremely crowded during the summer, are particularly vulnerable since they are proven to be concentrated accumulation zones and one of the main gateways of litter to enter the marine system. We found that the accumulation rates of marine litter on Mediterranean island beaches follow a seasonal pattern, increasing up to 4.7 times during the high season, representing a daily load of $(40.6 \pm 11.5) 10^{6}$ items/day extrapolated to all the islands of the region. We developed an accumulation index to assess the dynamics of marine litter and support efficient mitigation strategies by local authorities. To limit marine litter production attributable to recreational activities, a series of pilot actions implemented during the high touristic season, demonstrated a substantial reduction (up to 52.5\%). The implementation towards an efficient and sustainable tourism business model is urgently required.
\end{abstract}

\begin{abstract}
"Any persistent, manufactured or processed solid material discarded, disposed of or abandoned in the marine and coastal environment" is considered as marine litter ${ }^{1}$. Revealed during the late $1960 \mathrm{~s}$, the marine litter issue has received growing attention from the public ${ }^{2}$ with for example the foundation of the International Coastal Cleanup Programme in $1986^{3}$ and culminating in the 2000 s with the recognition of the microplastics (MPs) issue ${ }^{4}$ or the recent attempts to clean the oceans (e.g. The Ocean Cleanup Project ${ }^{5}$ ). Despite the different approaches implemented to tackle this contamination and which can be divided into four main categories ${ }^{6}$ (preventive, mitigating, removing and behavior-changing), the yearly amount of litter reaching the marine environment and mainly driven by plastic pollution remains tremendously high ${ }^{7,8}$.

With a coastal population of nearly 150 million inhabitants, the influx of freshwater from densely populated river catchments and a contribution to $15-30 \%$ of the global shipping activity ${ }^{9,10}$, the Mediterranean Sea has been recognized as one of the most affected areas in the world by marine litter ${ }^{11}$. In addition to these stressors, the countries surrounding the region yearly attract about one third of the world tourism ${ }^{12}$. Taken together, these anthropogenic pressures make this semi-enclosed sea, characterized by an anti-estuarine circulation ${ }^{13}$, an accumulation zone for marine litter, with for example concentrations of floating plastics debris comparable to those observed within the five subtropical gyres ${ }^{14-16}$. This high contamination of the Mediterranean Sea goes hand to hand with a stream of adverse effects to marine ecosystems, public health or socio-economic costs ${ }^{11}$.

At a global scale, beaches are one of the main land-based sources for litter to enter the marine environment through inadequate waste management, littering and illegal dumping ${ }^{17,18}$. The Mediterranean Sea is not an exception $^{11}$, particularly during the summer: the beaches of Mare Nostrum are a hotspot for leisure, especially for those who are looking for the three S's-sea, sand and sun ${ }^{19}$. Although beneficial for the sustainability of local communities, tourism may have detrimental socio-economic and environmental impacts ${ }^{20}$. This is particularly true for sea locked areas such as the islands of the region, which due to their attractiveness will host a far greater population during the summer ${ }^{21}$. In particular, coastal municipalities have to adapt and cope with the increase of the waste generated, including on the beaches, by the seasonal inflow of tourists ${ }^{22}$.
\end{abstract}

${ }^{1}$ Institute of Environmental Science and Technology (ICTA), Universitat Autònoma de Barcelona (UAB), Bellaterra, Spain. ${ }^{2}$ Catalan Institution for Research and Advanced Studies (ICREA), Barcelona, Spain. ${ }^{\square}$ email: michael.grelaud@uab.cat 
The cleanliness of the beaches being one of the main factors considered by the tourists, along with the scenery, the safety, the facilities and the water quality ${ }^{23}$, marine litter can represent, in addition to its negative environmental effects, a shortfall ${ }^{24}$ for local economies which often depend on this financial windfall. For example, in many countries, including those from the Mediterranean region, the absence of litter dictates visitors' choice (see Ref..$^{25}$ and references herein) and the probability to return to a given beach is strongly associated to the quality of the coastal environment ${ }^{26}$.

In this general context, it is then crucial to understand the seasonal dynamics of the waste generated by the visitors on the beaches in order to design effective solutions to mitigate this issue and move toward more sustainable tourism. Here we present the results of marine litter monitoring surveys performed on 24 beaches, going from remote to highly touristic sites, of Mediterranean islands during both the low and high touristic season of 2017. The results are compared to monitoring surveys performed on 11 of the same sites in 2019 after the implementation of pilot actions aiming at reducing the waste generated by the visitors.

Seasonal variation of beach litter in 2017. In order to evaluate the seasonal variation of marine litter as an effect of tourism on sandy beaches of Mediterranean islands, 147 surveys were conducted in 2017 during both the low and high touristic season, from February to November. For each of the eight participating islands (Mallorca-Spain, Sicily-Italy, Rab-Croatia, Malta-Malta, Crete, Mykonos and Rhodes-Greece, and Cyprus), three different beaches were selected: a very touristic beach $\left(\mathrm{T}_{\text {beach }}\right)$, a beach mainly used by locals $\left(\mathrm{L}_{\text {beach }}\right)$ and a remote beach $\left(\mathrm{R}_{\text {beach }}\right)$ with limited use by humans (Fig. 1 and "Methods"). For each beach, a periodic monitoring was performed on the same fixed $100 \mathrm{~m}$ portion ${ }^{27}$, covering the area going from the water line to the back of the beach $^{28}$ (Supplementary Fig. S1). Here, any item found was collected, characterized and properly disposed of. We included the smaller size classes of mesoplastics (MePs, $0.5-2.5 \mathrm{~cm}$ ), large microplastics (MPs, $0.1-0.5 \mathrm{~cm}$; i.e. visible to the naked eye), as well as pellets (raw plastic material), which usually are not targeted during this type of survey ${ }^{27}$.

A total of 162,320 items were collected. After correction for the distance and excluding one beach (see "Methods"), this represents an average of $1197.6 \pm 2978.0$ items per survey (or per $100 \mathrm{~m}$ of beach), $526.9 \pm 794.2$ items if we exclude the plastic fragments of less than $2.5 \mathrm{~cm}$. These results fall in the same order of magnitude as others studies carried out on Mediterranean Sea beaches ${ }^{11,29-34}$. The vast majority of the items collected belong to the artificial polymer materials (94.2\%; Supplementary Fig. S2), i.e. items partly or completely made of plastic. The average number of items collected per survey depends on the type of beach considered: the $\mathrm{L}_{\text {beach }}$ has an average of $2157.2 \pm 4680.2$ items $/ 100 \mathrm{~m}(\mathrm{n}=49)$, followed by the $\mathrm{T}_{\text {beach }} 899.9 \pm 858.8 \mathrm{items} / 100 \mathrm{~m}(\mathrm{n}=49)$ and the $\mathrm{R}_{\text {beach }}$ $425.4 \pm 1319.9$ items $/ 100 \mathrm{~m}(\mathrm{n}=42)$ (Fig. 2). Interestingly, when only the number of items collected is considered, no clear seasonal variation can be observed, no matter the type of beach considered (Fig. 2). Moreover, the number of items collected per $100 \mathrm{~m}$ of beach is always higher during the low season compared to the high season $\left(\times 1.03\right.$ for the $\mathrm{T}_{\text {beach }} \times 1.14$ for the $\mathrm{L}_{\text {beach }}$ and $\times 2.31$ for the $\left.\mathrm{R}_{\text {beach }}\right)$. These first results suggest that the seasonal increase of visitors on the beaches does not affect the amount of items of litter. This is counter intuitive as, for example, the amount of municipal solid waste generated during the high season on the island of Menorca (west Mediterranean Sea, Spain) is directly related to the number of tourists ${ }^{35}$.

For a given beach, by taking into account the time elapsed between the monitoring and the last cleaning performed by local authorities for the collected items larger than $5 \mathrm{~mm}$, the time elapsed between two consecutive monitoring for the items smaller than $5 \mathrm{~mm}$ (i.e. MPs and pellets), the surface monitored and the number of items collected, it is possible to estimate the accumulation rates (AR) of the marine litter (see "Methods"). During the high touristic season, the monitoring was done on average 6.2 days after the last cleaning for the $\mathrm{T}_{\text {beach }}, 13.2$ days for the $\mathrm{L}_{\text {beach }}$ and 27.8 days for the $\mathrm{R}_{\text {beach }}$, while during the low season, it was done respectively on average 61.2 days, 79.0 days and 105.3 days after. For some beaches, no cleaning activity was performed by the local authorities. In this case, we used the time elapsed between each monitoring to calculate the AR.

When the ARs are considered, a completely different picture emerges: the AR calculated for the three types of beach show an increase during the high touristic season (Fig. 3a). The $\mathrm{T}_{\text {beach }}$ has the highest accumulation with an average of $329.6 \pm 444.9$ items $/ 1000 \mathrm{~m}^{2} /$ day $(\mathrm{n}=33)$ during the high season, followed by the $\mathrm{L}_{\text {beach, }}$, $177.2 \pm 265.3$ items $/ 1000 \mathrm{~m}^{2} /$ day $(\mathrm{n}=33)$ and the $\mathrm{R}_{\text {beach }}, 13.7 \pm 32.2$ items $/ 1000 \mathrm{~m}^{2} /$ day $(\mathrm{n}=28)$. This represents an increase of the AR of $+471.9 \%$ for the $\mathrm{T}_{\text {beach }}$ and $+346.0 \%$ for the $\mathrm{L}_{\text {beach }}$ compared to the low season, when the AR are respectively of $69.8 \pm 110.1$ items $/ 1000 \mathrm{~m}^{2} /$ day $(\mathrm{n}=16)$ and $51.2 \pm 101.2 \mathrm{items} / 1000 \mathrm{~m}^{2} /$ day $(\mathrm{n}=16)$. For the $\mathrm{R}_{\text {beach, }}$, the high season increase is concealed by the high AR recorded in October-November (Fig. 3a). The ARs for this specific period fall in the same range as for the $\mathrm{T}_{\text {beach }}$ and the $\mathrm{L}_{\text {beach }}$. This could suggest that the impact of the visitors on the $\mathrm{R}_{\text {beach }}$ during the high season is lower than the "natural" beaching of the litter during the low season, which is usually characterized by worse weather conditions. This could possibly result in an increased wash up of the marine litter onto the beaches, even if very little is known about the processes that govern its beaching ${ }^{36}$. Then for the $\mathrm{R}_{\text {beach }}$, although a seasonal pattern is perceptible, the AR during the high season $\left[13.7 \pm 32.2\right.$ items $/ 1000 \mathrm{~m}^{2} /$ day $\left.(\mathrm{n}=28)\right]$ are on average $32.7 \%$ lower compared to the low season $\left[20.3 \pm 59.7\right.$ items $/ 1000 \mathrm{~m}^{2} /$ day $\left.(\mathrm{n}=14)\right]$.

To our knowledge, very few studies provide the necessary information to estimate the AR of marine litter on beaches ${ }^{37-41}$. Three of them were carried out on islands with very low anthropogenic pressure compared to our study: on a remote Aleutian island ${ }^{37}$, a remote island of the Hawaiian archipelago ${ }^{40}$ and a remote sub-Antarctic island ${ }^{38}$. In each case, the estimated ARs are up to 2-4 orders of magnitude lower than on the Mediterranean islands beaches, and up to 1-2 orders of magnitude lower if we consider beaches from the Mediterranean Sea ${ }^{34}$. For the study performed on a beach of eastern Australia ${ }^{39}$, the estimated ARs fall in the same range, highlighting the relationship between the number of items collected and the time elapsed since the last cleaning/monitoring. 

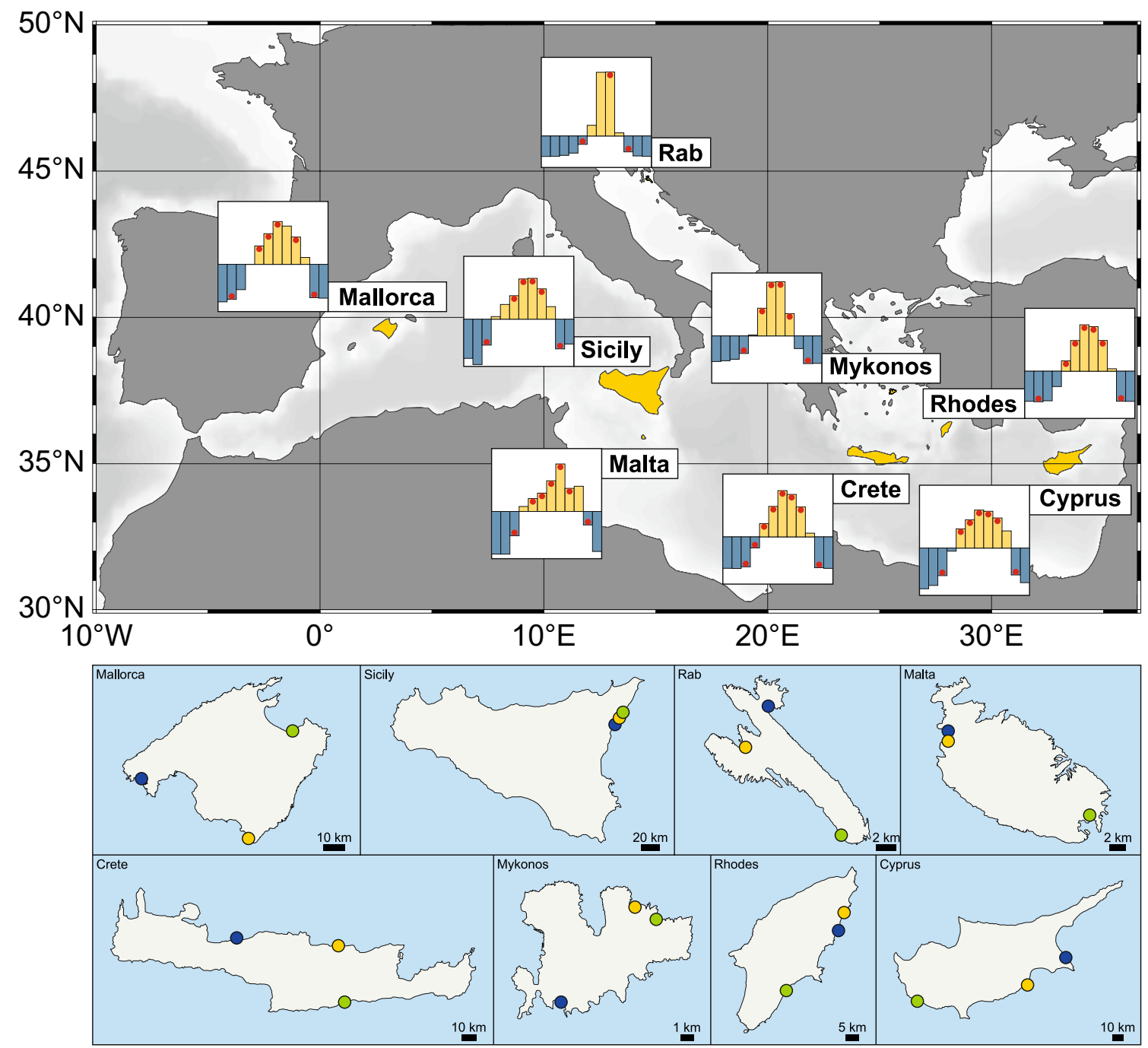

Figure 1. General map of the Mediterranean Sea. Top: the 8 islands selected for this study. The graphic next to each island shows the normalized monthly number of tourists (Y axis, arbitrary scale) welcome in 2016 or 2017 (X-axis, from January to December) (Supplementary Table S1). Yellow bars: high touristic season (monthly number of tourists above the annual average), blue bars: low touristic season (monthly number of tourists below the annual average). Red dots: marine litter surveys. Below: map of each island with the selected beaches $\left(\mathrm{T}_{\text {beach }}\right.$ : yellow dots, $\mathrm{L}_{\text {beach }}$ : blue dots and $\mathrm{R}_{\text {beach }}$ : green dots). The general map of the Mediterranean Sea was generated with Ocean Data View (Schlitzer, R., Ocean Data View, https://www.awi-bremerhaven.de/GEO/ODV, 2001).

Most frequent items and MePs-MPs possible source. Once corrected for distance, in order to make all the selected sites comparable (see "Methods"), the five most frequent items collected, were the MePs (35.3\%), cigarette butts (12.4\%), the MPs (11.2\%), pellets (9.5\%) and macroplastics (>2.5 $\mathrm{cm} ; 8.3 \%)$. The possible sources were classified according to the eight major categories described for the Adriatic and Ionian seas ${ }^{27}$. When we look at the items from the "shoreline, including poor waste management, tourism and recreational activities" (ST category, i.e. the items most likely left on the beaches by the visitors), the five most frequent for the surveys of 2017 are cigarette butts (12.4\%), plastic caps and lids (3.5\%), cutlery, trays and straws (1.6\%), crisp, sweet packets and lolly sticks (1.4\%) and metal bottle caps (0.7\%); in agreement with previous studies ${ }^{29,30}$. During the high season, these five items present as well the highest AR of the ST category no matter the type of beach considered, with the exception that for the $\mathrm{R}_{\text {beach }}$, the cutlery, trays and straws are replaced with metal drink cans (Supplementary Fig. S3). Unsurprisingly, cigarette butts have the highest AR with values of 173.5, 41.3 and 1.6 items $/ 1000 \mathrm{~m}^{2} /$ day measured respectively at the $\mathrm{T}_{\text {beach }}$, the $\mathrm{L}_{\text {beach }}$ and the $\mathrm{R}_{\text {beach }}$ during the high season.

Since the origin of small fragments/pieces of plastics cannot be clearly defined, we attributed the pellets to the "shipping" category, meaning that they are lost at sea during transportation. The MePs and the MPs are usually assigned to the "non-sourced" category. However, we observed a strong correlation between the AR of the MePs and the AR of the items from the ST category $\left(R^{2}=0.72, n=116, p<0.001\right)$, as well as between the AR of the MPs and the AR of the MePS $\left(\mathrm{R}^{2}=0.48, \mathrm{n}=87, p<0.001\right)$ (Fig. $\left.3 \mathrm{~b}\right)$, suggesting that the accumulation of small plastic fragments increases with the accumulation of the items of the ST category on the monitored beaches. From this observation, we hypothesize that a non-negligible part of both MePs and MPs could be produced directly on 


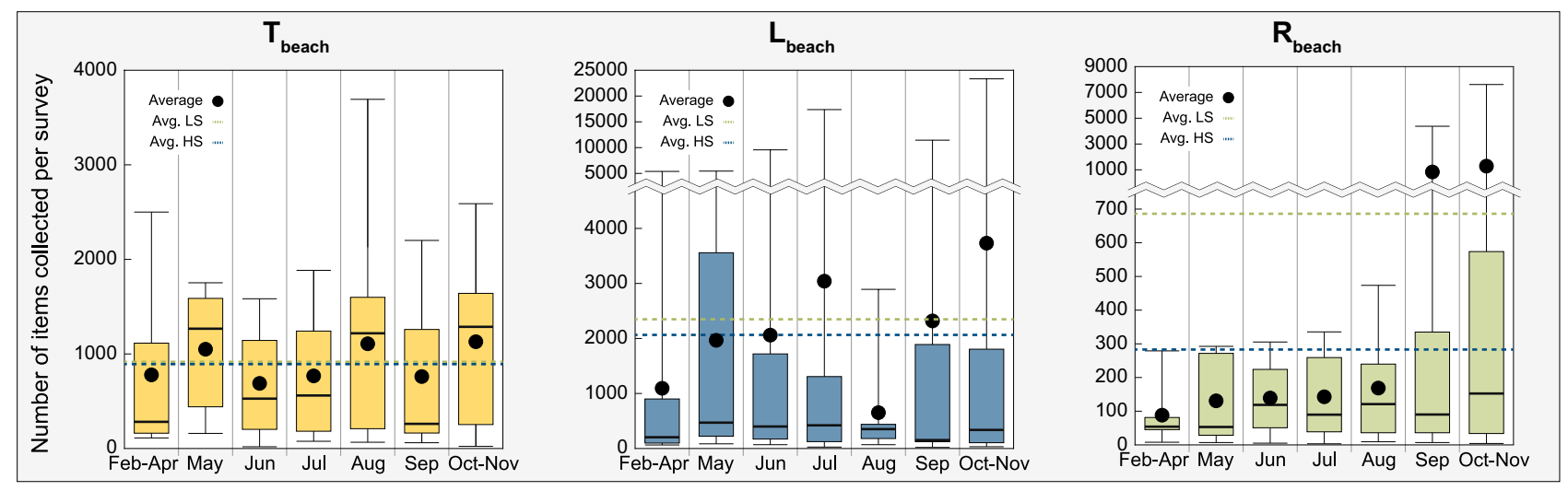

Figure 2. Number of items collected. Box plots showing the number of items collected on average per $100 \mathrm{~m}$ of beach ( $T_{\text {beach }}$ in yellow, $L_{\text {beach }}$ in blue and $R_{\text {beach }}$ in green). Note that the $R_{\text {beach }}$ from Malta was excluded (see "Methods"). Boxes represent the limits of the first and the third quartile. The line inside the boxes is the median and the extended lines are the maximum and the minimum number of items collected (note the broken $\mathrm{Y}$ axis with a different scale for $\mathrm{L}_{\text {beach }}$ and $\mathrm{R}_{\text {beach }}$ ). Black dots: average number of items collected, green dashed line: average number of items collected during the low season (LS) and blue dashed line: average number of items collected during the high season (HS).

the beaches by the fragmentation of larger plastic items ${ }^{42}$. During the summer in particular, plastic debris on beaches will undergo thermo-oxidative degradation ${ }^{43}$ by solar irradiance, and mechanical degradation ${ }^{43,44}$ by friction with the sand, accelerated by the high volume of visitors (our hypothesis).

Taken together, the AR of the items from the ST category, the MePs and the MPs show a clear seasonal pattern (Fig. 3a). This seasonal variation mimics the average number of tourists welcomed in the participating islands for the $\mathrm{T}_{\text {beach }}$ and the $\mathrm{L}_{\text {beach }}$ (Fig. 3a). During each month of the high season, the items from the ST category represent on average $65.7 \% \pm 2.8 \%\left(\mathrm{~T}_{\text {beach }}\right), 39.8 \% \pm 17.9 \%\left(\mathrm{~L}_{\text {beach }}\right)$ and $35.5 \% \pm 28.7 \%\left(\mathrm{R}_{\text {beach }}\right)$ of the items accumulating on the beaches, falling in the same range reported by previous studies ${ }^{29,34}$; and they increase respectively up to $79.2 \% \pm 4.5 \%, 77.9 \% \pm 9.4 \%$ and $58.8 \% \pm 19.1 \%$ if the MePs and the MPs are considered. The ARs of the other category items remain quite stable over the year (Fig. 3a). The highest AR for the MePs and MPs observed in the $\mathrm{L}_{\text {beach }}$ could be explained by the longer time elapsed between the monitoring and the last cleaning, allowing more time for larger plastic debris to fragment.

Accumulation index. We found that the use of a marine litter accumulation index (AI) is critical for assessing the impact of tourism on coastal sites and specifically on beaches. This AI, based on the AR, is divided into seven categories from extremely low to extremely high (Table 1). Contrary to the existing clean coast index ${ }^{45}$, which provides a snap shot of the cleanliness of a beach, the AI enables the assessment of marine litter dynamics. The AI can be applied at different time scales (month or season) and for general or specific items of marine litter. Here we present the marine litter AI, for each Mediterranean island and for each type of beach monitored in this study (Fig. 4). In all cases, the AI is always higher during the high season compared to the low season, no matter the type of beach considered. The AI can be used as an indicator for municipalities to identify, address and mitigate the seasonal variation of waste generation on beaches resulting from tourism, by highlighting for example the most frequent items abandoned and to raise awareness in order to change visitors' behavior.

Positive impact of awareness campaigns on marine litter AR. Following the results obtained in 2017, pilot actions were conducted during the 2019 high season on 11 beaches previously monitored: both the $\mathrm{T}_{\text {beach }}$ and $\mathrm{L}_{\text {beach }}$ of Sicily, Malta, Crete, Rhodes and Cyprus; and the $\mathrm{T}_{\text {beach }}$ of Mallorca. Due to the very low $\mathrm{AR}$ measured during the 2017 high season in the $\mathrm{R}_{\text {beach }}$, no pilot actions were implemented there. The pilot actions consisted mainly in awareness campaigns ${ }^{46}$ through the distribution of flyers and the installation of posters at the main entrances of the beaches showing the results obtained in 2017 and emphasizing the potential role of the visitors on beach litter generation ( 11 beaches), the availability of ashtrays ( 6 beaches) and the intervention of representatives informing the visitors of the marine litter issue and its prevention ( 9 beaches). Moreover, when nonexistent, new trash bins were installed on the beaches and the existent ones, when necessary, were adapted to collect both mixed and recycled waste, with bilingual indications (national language and English) (5 beaches).

The surveys were conducted in August or September 2019, between two weeks and two months after the beginning of the implementation of the pilot activities and on average 6.7 days $\left(\mathrm{T}_{\text {beach }}\right)$ and 35.1 days $\left(\mathrm{L}_{\text {beach }}\right)$ after the last cleaning of the beaches. The surveys were carried out on the exact same portions of beach as for 2017 and following the exact same procedure. However, it has been only possible to conduct one survey per site. This constraint made impossible to estimate the AR for the MPs and pellets, the smallest items, after the implementation of the pilot actions. With the exception of the $\mathrm{L}_{\text {beach }}$ of Sicily which shows a more than sixfold increase of the AR of the items from the ST category, the 10 other sites show a decrease of their AR ranging from $-20.8 \%$ ( $\mathrm{T}_{\text {beach }}$ of Cyprus) to $-98.8 \%$ ( $\mathrm{L}_{\text {beach }}$ of Rhodes) (Supplementary Fig. $\mathrm{S} 4$ ). 


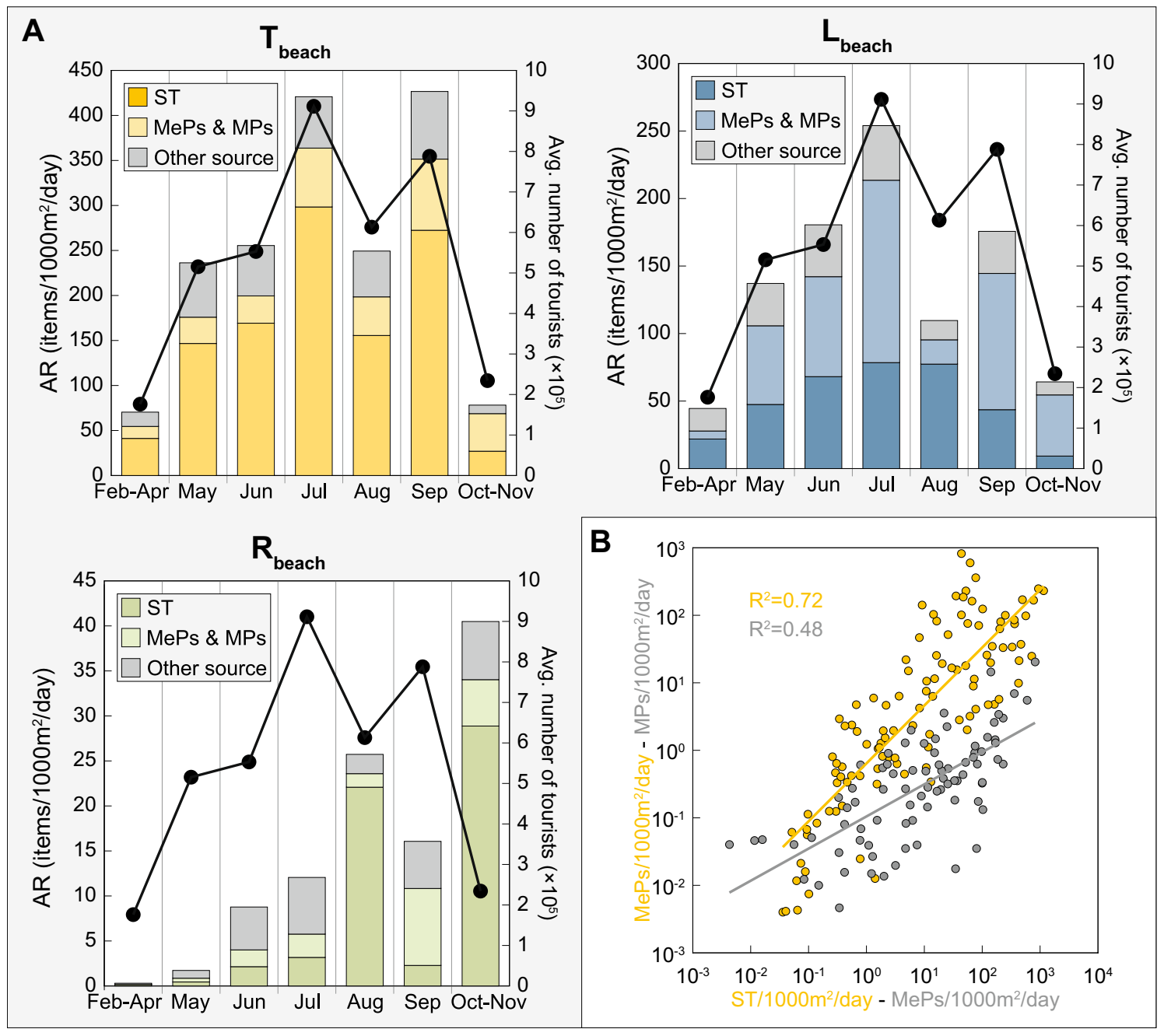

Figure 3. Accumulation rates of marine litter by source. (A) AR over time of the items from the "shoreline, including poor waste management, tourism and recreational activities" category (ST, dark color), the MePs and MPs (light color) and all the others categories (grey color). The black dots and lines represent the average monthly number of tourists welcomed in the islands where monitoring was performed (Supplementary Table S1). The decrease observed during August for the AR of the $\mathrm{T}_{\text {beach }}$ and the $\mathrm{L}_{\text {beach }}$ as well as for the average number of tourists is related to the absence of monitoring performed on the island of Mallorca, which is the most visited island and one of the most affected by marine litter. (B) Comparison between the AR of the MePs and the AR of the items from ST category (yellow); and between the AR of the MPs and the AR of the MePs (grey). The solid yellow and grey lines represent the power regression for both comparisons (both X and Y axes are on a logarithmic scale).

\begin{tabular}{|l|l|l|l|l|l|l|l|}
\hline Quality & Extremely low & Very low & Low & Moderate & High & Very high & Extremely high \\
\hline $\mathrm{AI}(\log 10(\mathrm{AR} \times 1000))$ & $\leq 1$ & $1-2$ & $2-3$ & $3-4$ & $4-5$ & $5-6$ & $\geq 6$ \\
\hline $\mathrm{AR}\left(\# \mathrm{items} / 1000 \mathrm{~m}^{2} /\right.$ day $)$ & $0.01 \leq$ & $0.01-0.1$ & $0.1-1$ & $1-10$ & $10-100$ & $100-1000$ & $\geq 1000$ \\
\hline
\end{tabular}

Table 1. Accumulation Index (AI), value and equivalence for the accumulation rates (AR).

For the $6 \mathrm{~T}_{\text {beach }}$ tested, the average AR of the items belonging to the ST category were of $340.3 \pm 410.7$ items $/ 1000 \mathrm{~m}^{2} /$ day in 2017 and of $178.1 \pm 200.2$ items $/ 1000 \mathrm{~m}^{2} /$ day in 2019 , representing an average decrease of $-47.7 \%$ of the AR. For the $\mathrm{L}_{\text {beach }}$ tested, after excluding the beach of Sicily (Supplementary Fig. S4), the average AR of the items from the ST category were of $60.8 \pm 94.1$ items $/ 1000 \mathrm{~m}^{2} /$ day in 2017 and of $30.3 \pm 40.7$ items $/ 1000 \mathrm{~m}^{2} /$ day in 2019 . This represents an average decrease of $50.1 \%$ of the accumulation of the litter left on the beaches by the visitors (Fig. 5). For the $\mathrm{T}_{\text {beach }}$ tested, the decrease of the AR of the ST category items is concomitant to a decrease of the AR of both MePs $(-31.3 \%)$ and remaining litter $(-43.6 \%$, MPs and pellets being excluded), while for the $\mathrm{L}_{\text {beach }}$ tested it is concomitant to an increase of the AR of both the MePs $(+26.0 \%)$ and remaining litter (+106.7\%, MPs and pellets being excluded) (Fig. 5). Regarding the the MePs, the increase of 


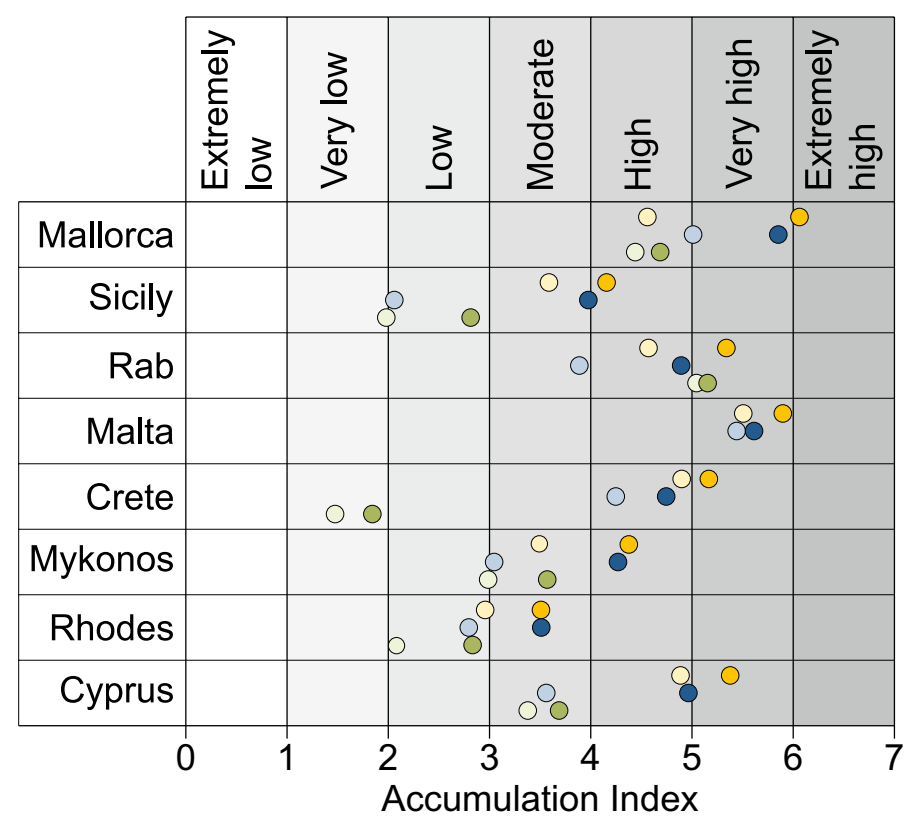

Figure 4. Accumulation Index of the 24 selected beaches. The AI calculated for the low season (LS) are given by the light colors and the AI for the high season (HS) by the dark colors. $\mathrm{T}_{\text {beach }}$ : yellow, $\mathrm{L}_{\text {beach }}$ : blue and $\mathrm{R}_{\text {beach }}$ : green.

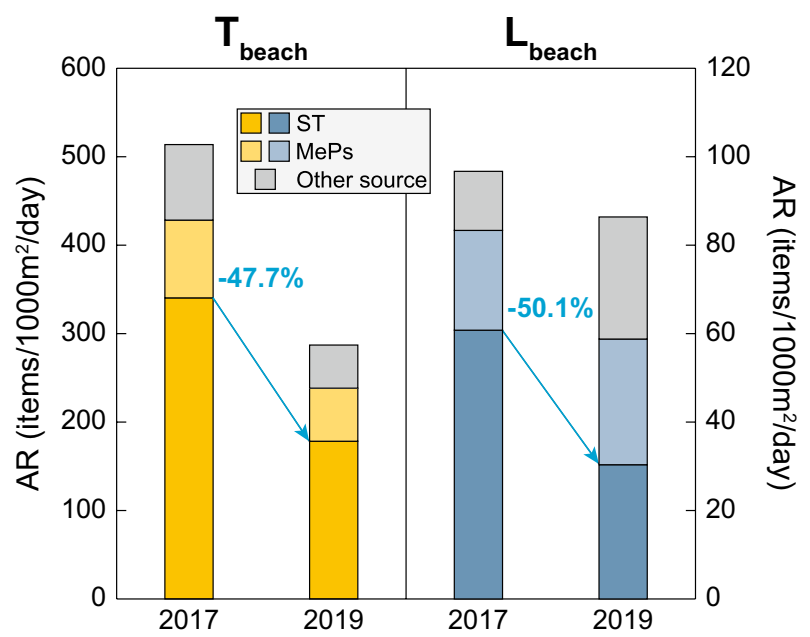

Figure 5. Impact of the pilot actions. AR of the items from the ST category, the MePs and the remaining items (excluding MPs and pellets) measured in August/September2017 and in August/September 2019 after the implementation of the pilot actions. The light blue percentages provide the decrease of the AR for the ST category between 2017 and 2019.

the $\mathrm{AR}$ on the $\mathrm{L}_{\text {beach }}$ could again be explained by a much longer time elapsed between the last cleaning activities and the surveys. However, the difference regarding the other remaining items (i.e. not from the ST category or the MePs), cannot be explained by our results. Although it is possible to imagine that local/regional differences about the beaching of the litter, especially for islands from distinct sub-basins of the Mediterranean Sea, could play a significant role.

According to the results from 2017, cigarette butts are the most common item left on the beaches by the visitors. Ashtrays were then made available for the visitors on the 2 selected beaches of Malta, Crete and Cyprus. The accumulation rates of cigarette butts for these 6 beaches decreased on average by $54.5 \%( \pm 12.0 \%)$ after the implementation of the pilot actions. For the beaches where no ashtrays were made available ( $\mathrm{T}_{\text {beach }}$ of Mallorca, Sicily and Rhodes; $\mathrm{L}_{\text {beach }}$ of Rhodes), we observed a decrease of $57.8 \%( \pm 28.2 \%)$ between 2017 and 2019. No significant difference between the two groups of beaches is observed ( $p$-value $>0.05$ ). We do not interpret this as an ineffectiveness of the ashtrays to reduce the number of cigarette butts thrown on the beach, but rather as an 
increase of the proportion of visitors who possibly refrain from smoking on the beach or who properly disposed of the cigarette butts whether ashtrays are available or not. Interestingly, the only beach which shows an increase of the AR of the cigarette butts in particular $(8 \times)$ or of the items of the ST category in general $(6 \times)$ was the $\mathrm{L}_{\text {beach }}$ of Sicily where no representative was present to inform the visitors and no ashtrays were made available.

Regarding the four other most abundant items, they all show a decrease of their AR on the tested $\mathrm{T}_{\text {beach }}$ : $-51.8 \%$ for the plastic caps and lids, $-74.0 \%$ for the cutlery, trays and straws, $-59.5 \%$ for the crisp, sweet packets and lolly sticks, and $-40.6 \%$ for the metal bottle caps. For the $\mathrm{L}_{\text {beach }}$ considered (excluding Sicily), with an exception for the crisp, sweet packets and lolly sticks which shows an increase of $+153.8 \%$ ( 2 items collected in 2017 vs. 59 in 2019 for these 3 beaches), the other items present a similar decrease of their AR by - 50.7\% (plastic caps and lids), $-65.0 \%$ (cutlery, trays and straws) and $-42.4 \%$ (metal bottle caps) (Supplementary Fig. S5).

The recreational use of beaches as a main source for marine litter. Massive tourism in Mediterranean islands and specifically in their beaches is a main driver of marine litter generation. Popular beaches ( $\mathrm{T}_{\text {beach }}$ and $\mathrm{L}_{\text {beach }}$ ) are clearly the most impacted sites of this study. Every day, during the high touristic season peak (July-August), on every $100 \mathrm{~m}$ of beach, visitors will leave on average $844.5\left(\mathrm{~T}_{\text {beach }}\right)$ and $295.2\left(\mathrm{~L}_{\text {beach }}\right)$ items from the ST category. This represent respectively $71.0 \%$ and $31.1 \%$ of the total amount of items composing the marine litter during this specific period. If the MePs and the MPs are included, resulting from the fragmentation of larger plastic items as we hypothesized, then visitors could generate in total 1028.4 items $\left(\mathrm{T}_{\text {beach }}\right.$ ) and 798.3 items $\left(\mathrm{L}_{\text {beach }}\right)$, representing this time respectively up to $86.4 \%$ and $84.0 \%$ of the total amount of items composing the marine litter during this specific period. Once again it is worth noting that on average 2.7 times more MePs and MPs are generated on the $\mathrm{L}_{\text {beach }}$ compared to the $\mathrm{T}_{\text {beach }}$ during the high season peak. To our point of view it is clear that the frequency of the cleaning of the beaches by the local authorities play an important role regarding the prevention of the generation of MPs and MePs as the $\mathrm{T}_{\text {beach }}$ are cleaned on average 2.1 times as often as the $\mathrm{L}_{\text {beach }}$. For the $\mathrm{R}_{\text {beach }}$, tourism could be responsible of the accumulation of 57.7 items per $100 \mathrm{~m}$ of beach per day, meaning that the remote sites are on average 14-20 times less impacted than the most popular beaches.

Even if the $\mathrm{T}_{\text {beach }}$ and $\mathrm{L}_{\text {beach }}$ are frequently cleaned during the high season, the portion of the marine litter accumulating on these beaches and reaching the sea, although hardly assessable, could represent a tremendous daily load as Mediterranean islands account for about $19000 \mathrm{~km}$ of coastline ${ }^{47}$. At the region scale, we estimated that during the high season peak (July-August), visitors could be responsible for the accumulation of about $40.610^{6} \pm 11.510^{6}$ items/day on the beaches of the Mediterranean islands ("Methods"). As a matter of fact, if all these items were to reach the marine environment, this would represent the equivalent of a daily accumulation of $2500 \pm 709$ items $/ \mathrm{km}$ along the Mediterranean islands coastline. Although hypothetical, this value is quite realistic when compared to concentrations of floating plastic in the nearshore water strip (i.e. $<1 \mathrm{~km}$ off the coasts $)^{48}$ ranging from 28,000 to 578,000 items $/ \mathrm{km}^{2}$.

Awareness campaigns, a promising tool to reduce beach littering. Our results show that awareness campaigns could be an efficient tool to reduce the amount of litter resulting from the recreational use of the Mediterranean island beaches. Indeed, we observed an average decrease of $52.5 \% \pm 20.8 \%$ of the AR of the items from the ST category after the implementation of the pilot actions. These very encouraging results probably benefit from the growing attention of the public to the plastic pollution in the oceans or the measures adopted by the European Commission to reduce marine litter (e.g. the single-use plastic directive). However, this reduction of the marine litter has a price: to achieve these results, the average cost of the pilot actions, extrapolated to the whole high season (May-September) would be of $111.6 \mathrm{k} €$ per $\mathrm{km}$ of beach ${ }^{49}$. This cost could be restrictive for local authorities to implement such actions.

The number of visitors in the Mediterranean region is projected to increase rapidly with more than 500 million expected tourists by $2030^{50}$. There is an urgent need for a tourism lifestyle change and environmental education of key actors acting on the knowledge gaps of policy-making processes and on the investment in sustainable tourism. Proper monitoring of tourism sustainability is a strategic driver for the economic development and sustainability of islands that depends on ecosystem services already threatened by climate change.

\section{Methods}

Sampling strategy. In order to assess the seasonal variation of marine litter as an effect of tourism on Mediterranean islands, 24 beaches ( 3 per island) have been monitored for marine litter during both the low and high seasons. For each selected site, a fixed $100 \mathrm{~m}$ portion of beach (i.e. sampling unit) was defined, as recommended in most beach litter monitoring methodologies ${ }^{27,28,51,52}$, and going from the waterline to the back of the beach as the visitors can occupy any point within this zone. Moreover, the sampling unit should be connected, when possible, to at least one access to the beach around which the density of visitors is usually the highest, especially for the $\mathrm{T}_{\text {beach }}$ and $\mathrm{L}_{\text {beach. }}$. As on some islands the beaches can be very small $(<200 \mathrm{~m})$ and narrow $(<10 \mathrm{~m})$, the monitoring of more than one sampling unit ${ }^{27,51}$ could not be implemented and the monitoring of few (very short) random transects ${ }^{52}$ within one sampling unit possibly not representative. By taking into account all these points, we decided to use the OSPAR methodology ${ }^{28}$ for the 24 selected beaches and adapt it in order to include the MePS, the MPs and the pellets.

Once defined, the fixed $100 \mathrm{~m}$ portions have been periodically monitored for marine litter: once a month during the high touristic season (from May to September) and one time before (February-April) and after (October-November) the high season. Although, the same fixed portion was always monitored for each beach, it appears that for some of them, the surface monitored slightly changed from one survey to another, depending on various factors such as the accuracy of the GPS, the presence of vehicles or the crowd on the beach. The highest variations were observed in August and September for the $\mathrm{T}_{\text {beach }}$ of Malta where only one third of the 
defined surface was monitored. During the monitoring, all the items with an anthropogenic origin found on the sand were collected, counted and characterized ${ }^{28}$.

During the surveys, the small plastic pieces including the mesoplastics (MePs, $0.5-2.5 \mathrm{~cm}$ ), the large microplastics (MPs, $0.1-0.5 \mathrm{~cm}$ ) and the pellets (raw plastic material) were collected at the same time as the larger marine litter items and on the same portion of beach. The surveyors had the instruction to only collect the small items laying directly on the surface of the sand (i.e. plastic debris/pellet buried below the surface of the sand were not monitored). Moreover, during a monitoring, there was one surveyor assigned to the collection of these small plastic items who was helped by the others surveyors once the bigger marine litter items were collected. The small pieces of plastic were then shipped to our institute, sorted according to their size and assigned to one of the following categories: macroplastics $(>2.5 \mathrm{~cm})$, MePS $(0.5-2.5 \mathrm{~cm}), \mathrm{MPs}(<0.5 \mathrm{~cm})$ or pellets. Note that for the pellets, all the particles recognized as such were counted as pellets, no matter their size.

For each island, the 3 different beaches were selected as follows in order to include (1) an impact site $\left(\mathrm{T}_{\text {beach }}\right)$ where tourists represent most of the visitors to the beach, (2) a control site $\left(\mathrm{L}_{\text {beach }}\right)$ where locals represent most of the visitors and (3) a remote/preserved site $\left(\mathrm{R}_{\text {beach }}\right)$ where the frequency of both tourists and locals is low. $\mathrm{T}_{\text {beach }}$ are characterized by a high volume of visitors, mainly tourists, especially during the high touristic season. In the area situated directly behind the beach high levels of infrastructure dedicated to tourism and recreational activities, such as hotels, restaurants, bars, souvenir shops, etc., are found. $\mathrm{L}_{\text {beach }}$ are characterized by high volume of visitors, mainly locals, especially during the high touristic season. However, in the area situated directly behind the beach low level of infrastructures dedicated to tourism and recreational activities, such as hotels, restaurants, bars, souvenir shops, etc., are found. $\mathrm{R}_{\text {beach }}$ are assumed to be the less impacted type of beach. They are characterized by low volume of visitors, even during the high touristic season. In the area situated directly behind the beach no infrastructure dedicated to tourism and recreational activities are found.

Regarding this last type of beach, although 8 beaches were monitored in 2017, we had to remove the results obtained from Malta. The volume of visitors, although reduced, cannot be considered comparable to other remote beaches of this study. It is situated in the municipality of Marsaxlokk and a harbor is bordering the beach to the west. Moreover the total number of items collected on this beach (4249) represents more than $20 \%$ of the total number of items collected on all the $\mathrm{R}_{\text {beach }}(20,738)$, and once calculated the accumulation rates of marine litter for this specific beach appears to be 60 times higher $\left(956.6\right.$ items $/ 1000 \mathrm{~m}^{2} /$ day) than the average accumulation rates calculated for the others $\mathrm{R}_{\text {beach }}\left(15.9\right.$ items $/ 1000 \mathrm{~m}^{2} /$ day), making the $\mathrm{R}_{\text {beach }}$ of Malta not suitable for the analysis.

Data compilation and analysis. For each of the 24 selected beaches a fixed $100 \mathrm{~m}$ portion of beach was defined. The coordinates of the starting point and the ending point of the portion were recorded and the distance between the two points was calculated with the following equation:

$$
D=\cos ^{-1}\left(\sin \left(\operatorname{rad}\left(\text { Lat }_{S}\right)\right)+\cos \left(\operatorname{rad}\left(\text { Lat }_{S}\right) \times \cos \left(\operatorname{rad}\left(\text { Lat }_{E}\right)\right) \times \cos \left(\operatorname{rad}\left(\text { Long }_{S}-\text { Long }_{E}\right)\right)\right) \times 6371 \times 1000,\right.
$$

where $D$ is the calculated distance in $\mathrm{m}, \mathrm{Lat}_{S}$ is the starting latitude (in decimal degree), Long $_{S}$ the starting longitude (in decimal degree), $L_{a t}$ the ending latitude (in decimal degree) and Long $_{E}$ the ending longitude (in decimal degree). The functions $\cos ^{-1}$ returns the arccosine of an angle, cos returns the cosine of an angle, sin returns the sine of an angle and rad converts degrees into radians. When $D$ is not equal to $100 \mathrm{~m}$ (most of the cases) the number of items collected on the portion were corrected for the distance in order to normalize all the data for all the beaches. The following equation was used to correct the data:

$$
N I_{\text {cor }}=N I_{\text {col }} \times 100 / D,
$$

where $N I_{c o r}$ is the number of items corrected for distance, $N I_{c o l}$ the number of items collected on the fixed portion of beach and $D$ the calculated distance from Eq. (1). Note that the number of items corrected for distance is only used to show the number of items per $100 \mathrm{~m}$ of beach: it is not used for the calculation of the accumulation rates or the accumulation index.

Finally, for each beach, the surface of the $100 \mathrm{~m}$ fixed portion was estimated by using the "Polygon" tool from Google Earth. For each beach, the considered surface was measured from the water line to the back of the beach, between the starting and the ending points of the portion.

The accumulation rates of the marine litter is used here to estimate the accumulation of marine litter or of a given item per unit of surface and per unit of time. In this study the accumulation rates are given in number of items $/ 1000 \mathrm{~m}^{2} /$ day. It is calculated as follows:

$$
A R=\left(N I_{c o l} / S / T\right) \times 1000,
$$

where $A R$ is the accumulation rate in number of items $/ 1000 \mathrm{~m}^{2} /$ day, $N I_{\text {col }}$ the number of items collected on the fixed portion of beach (not corrected for the distance), $S$ the surface of the fixed portion of beach in $\mathrm{m}^{2}$ and $T$ the time elapsed between the survey and the last cleaning activity in days. The time elapsed since the last cleaning corresponds to the number of days elapsed since the last cleaning performed by the local authorities (or the previous survey when no cleaning activities were conducted by the local authorities). The AR of the MPs and pellets were always calculated by taking into account the time elapsed between each survey and not the time elapsed since the last cleaning, as due to their small size we assumed these particles cannot be removed even with mechanical cleaning. Moreover, for the very first survey performed on each beach, the AR of the MPs and the pellets were arbitrarily calculated by using the number of days elapsed between the survey and the 1st of January 2017 as it was not possible to estimate since when these particles were accumulating on the beaches. Then the average number of days used for the calculation was $83.6,83.6$ and 87.3 respectively for the $\mathrm{T}_{\text {beach }}$, the $\mathrm{L}_{\text {beach }}$ and the $\mathrm{R}_{\text {beach }}$. 
The accumulation index (AI) was developed for this study. This index takes into account the accumulation rates of the marine litter and can be calculated as follows:

$$
A I=\log _{10}(A R \times 1000)
$$

where $A I$ is the accumulation index and $A R$ the accumulation rate (see Eq. 3 ) in number of items $/ 1000 \mathrm{~m}^{2} /$ day.

Composition of the marine litter. The composition of the marine litter was estimated by grouping the items into nine different categories, following the EU MSFD TG10 "Guidance on Monitoring of Marine Litter in European Seas" ${ }^{33}$ : artificial polymer materials, rubber, cloth/textile, paper/cardboard, processed/worked wood, metal, glass/ceramics, unidentified and chemicals. No matter the type of beach considered or the month of the monitoring, the marine litter collected was largely dominated by the artificial polymer materials category (Supplementary Fig. S2). On average, this category represents for the $\mathrm{T}_{\text {beach, }}, \mathrm{L}_{\text {beach }}$ and $\mathrm{R}_{\text {beach }}$, respectively $87.9 \% \pm 3.1 \%, 97.3 \% \pm 1.8 \%$ and $85.9 \% \pm 11.8 \%$ of the items collected during the low season, and respectively $87.7 \% \pm 8.6 \%, 95.9 \% \pm 4.0 \%$ and $88.1 \% \pm 5.3 \%$ of the items collected during the high season.

Seasonality. To make the distinction between the low and the high touristic season, the number of visitors welcomed in each island in 2017 was used, with the exception of the island of Rab (Croatia) where only the data for 2016 are available (Supplementary Table S1). These data were normalized (standard score method) in order to highlight the low and high seasons (Fig. 1).

Pilot actions implementation. In 2019, both the $\mathrm{T}_{\text {beach }}$ and $\mathrm{L}_{\text {beach }}$ of Sicily, Malta, Crete, Rhodes and Cyprus, and the $\mathrm{T}_{\text {beach }}$ of Mallorca were selected to carry out pilot actions in order to reduce the amount of waste that enters the environment through beaches. These activities were implemented during the summer 2019 and consisted in, amongst other, awareness campaigns directly on sites (i.e., on beaches or the area surrounding them) or through social media or radio, installation of new trash bins for mixed or recyclable waste, or the installation of new signs on existing bins. A complete description of the pilot actions can be found here ${ }^{46}$.

Extrapolation for all Mediterranean islands. In order to extrapolate the accumulation of marine litter for all the Mediterranean island beaches, we proceed as follows: first the total coastline length of each of the eight islands was extracted from the "CCM River and Catchment Database", JRC/IES (https://agrienv.jrc.it/activities /catchments/) with ArcGIS. Then the total length of each island's beaches was measured using the "path" tool from Google Earth (Supplementary Table S2). On average, the beaches represent about $34.0 \% \pm 11.9 \%$ of the coastline. This proportion is in agreement with previous study for the Mediterranean $\mathrm{Sea}^{47}$, as $54 \%$ of the coastlines are rocky and the remaining $46 \%$ include beaches, dunes, reefs, lagoons, estuaries and deltas.

During the peak of the high season (July-August), the average AR of marine litter of the ST category, of the MePs and of the MPs taken together represent $1028.4 \mathrm{items} / 100 \mathrm{~m} /$ day, $798.3 \mathrm{items} / 100 \mathrm{~m} / \mathrm{day}$ and 57.7 items $/ 100 \mathrm{~m} /$ day respectively for the $\mathrm{T}_{\text {beach }}, \mathrm{L}_{\text {beach }}$ and $\mathrm{R}_{\text {beach }}$. This represents an average of 628.1 \pm 507.2 items/100 m/day.

We estimated that beaches of Mediterranean islands account for $6466.5 \mathrm{~km} \pm 2268.0 \mathrm{~km}$ and that the items left on beaches by the visitors could account for $40.610^{6} \pm 11.510^{6}$ items/day.

\section{Data availability}

The seasonal marine litter abundances and accumulation rates dataset used in this work are available at https:// doi.org/10.1594/PANGAEA.923731.

Received: 18 August 2020; Accepted: 9 November 2020

Published online: 23 November 2020

\section{References}

1. UNEP Regional Seas Programme, UNEP. Marine Litter: An Analytical Overview (UNEP, 2005). http://hdl.handle.net/20.500.11822 18348.

2. Ryan, P. G. A brief history of marine litter research. In Marine Anthropogenic Litter 1-25 (Springer International Publishing, New York, 2015). https://doi.org/10.1007/978-3-319-16510-3_1.

3. International Coastal Cleanup (ICC) Ocean Conservancy. In The 30th Anniversary of the International Coastal Cleanup. (2016).

4. Thompson, R. C. et al. Lost at sea: Where is all the plastic?. Science (80-). 304, 838-838 (2004).

5. The Ocean Cleanup Project. https://theoceancleanup.com/.

6. Chen, C. L. Regulation and management of marine litter. In Marine Anthropogenic Litter 395-428 (Springer International Publishing, New York, 2015). https://doi.org/10.1007/978-3-319-16510-3 15.

7. Jambeck, J. R. et al. Plastic waste inputs from land into the ocean. Science (80-). 347, 768-771 (2015).

8. Lebreton, L. C. M. et al. River plastic emissions to the world's oceans. Nat. Commun. 8, 15611 (2017).

9. UNEP/MAP. State of the Mediterranean marine and coastal environment. In United Nations Environment Programme/Mediterranean action plan (UNEP/MAP) - Barcelona convention: Athens 96 (2012). https://doi.org/10.13140/RG.2.1.3013.2648.

10. Compa, M. et al. Nearshore spatio-temporal sea surface trawls of plastic debris in the Balearic Islands. Mar. Environ. Res. 158, 104945 (2020).

11. UNEP/MAP. Marine Litter Assessment in the Mediterranean. (2015). http://hdl.handle.net/20.500.11822/7098.

12. World Tourism Organization. UNWTO Tourism Highlights. 2018 edn (UNWTO, Madrid, 2018). https://doi.org/10.18111/97892 84419876.

13. Pinardi, N. \& Masetti, E. Variability of the large scale general circulation of the Mediterranean Sea from observations and modelling: A review. Palaeogeogr. Palaeoclimatol. Palaeoecol. 158, 153-173 (2000).

14. Cózar, A. et al. Plastic accumulation in the mediterranean sea. PLoS ONE 10, 1-12 (2015). 
15. Eriksen, M. et al. Plastic pollution in the world's oceans: More than 5 trillion plastic pieces weighing over 250,000 Tons Afloat at Sea. PLoS ONE 9, e111913 (2014).

16. Lebreton, L.C.-M., Greer, S. D. \& Borrero, J. C. Numerical modelling of floating debris in the world's oceans. Mar. Pollut. Bull. 64, 653-661 (2012).

17. Kershaw, P. et al. Exploring the Potential for Adopting Alternative Materials to Reduce Marine Plastic Litter (United Nations Environment Programme (UNEP), Nairobi, 2018). ISBN 978-92-807-3703-5.

18. Veiga, J. M. et al. Identifying Sources of Marine Litter. MSFD GES TG Marine litter Thematic Report. JRC Technical Report. (2016). https://doi.org/10.2788/018068.

19. Dodds, R. \& Kelman, I. How climate change is considered in sustainable tourism policies: A case of the Mediterranean Islands of Malta and Mallorca. Tour. Rev. Int. 12, 57-70 (2008).

20. Plan Bleu. Tourism and sustainability in the Mediterranean: Key facts and trends (Plan Bleu, Regional Activity Centre, Valbonne, 2016). https://planbleu.org/sites/default/files/publications/tourism_and_sustainability_june2016.pdf.

21. Fortuny, M., Soler, R., Cánovas, C. \& Sánchez, A. Technical approach for a sustainable tourism development. Case study in the Balearic Islands. J. Clean. Prod. 16, 860-869 (2008).

22. Drius, M. et al. Tackling challenges for Mediterranean sustainable coastal tourism: An ecosystem service perspective. Sci. Total Environ. 652, 1302-1317 (2019).

23. Williams, A. \& Micallef, A. Beach Management, Principles and Practice (EarthScan, London, 2009).

24. Watkins, E. et al. Marine Litter Socio Economic Study. A Report by IEEP for UNEP. (2017). http://hdl.handle.net/20.500.11822 126014 .

25. Zielinski, S., Botero, C. M. \& Yanes, A. To clean or not to clean? A critical review of beach cleaning methods and impacts. Mar. Pollut. Bull. 139, 390-401 (2019).

26. Schuhmann, P. W. Tourist perceptions of beach cleanliness in barbados: Implications for return visitation. Études caribéennes https ://doi.org/10.4000/etudescaribeennes.5251 (2012).

27. Vlachogianni, T. et al. Marine litter assessment in the Adriatic and Ionian Seas. IPA-Adriatic DeFishGear Project, MIO-ECSDE, HCMR and ISPRA. (2017). ISBN: 978-960-6793-25-7.

28. Wenneker, B. \& Oosterbaan, L. Guideline for Monitoring Marine Litter on the Beaches in the OSPAR Maritime Area. OSPAR Commission. (2010). ISBN: 90-3631-973-9.

29. Vlachogianni, T. et al. Marine litter on the beaches of the Adriatic and Ionian Seas: An assessment of their abundance, composition and sources. Mar. Pollut. Bull. 131, 745-756 (2018).

30. Munari, C., Corbau, C., Simeoni, U. \& Mistri, M. Marine litter on Mediterranean shores: Analysis of composition, spatial distribution and sources in north-western Adriatic beaches. Waste Manag. 49, 483-490 (2016).

31. Gabrielides, G. P. et al. Man-made garbage pollution on the Mediterranean coastline. Mar. Pollut. Bull. 23, 437-441 (1991).

32. Martinez-Ribes, L., Basterretxea, G., Palmer, M. \& Tintoré, J. Origin and abundance of beach debris in the Balearic Islands. Sci. Mar. 71, 305-314 (2007).

33. Bowman, D., Manor-Samsonov, N. \& Golik, A. Dynamics of litter pollution on Israeli Mediterranean beaches: A budgetary, litter flux approach. J. Coast. Res. 14, 418-482 (1998).

34. Prevenios, M. et al. Beach litter dynamics on Mediterranean coasts: Distinguishing sources and pathways. Mar. Pollut. Bull. 129, 448-457 (2018).

35. Mateu-Sbert, J., Ricci-Cabello, I., Villalonga-Olives, E. \& Cabeza-Irigoyen, E. The impact of tourism on municipal solid waste generation: The case of Menorca Island (Spain). Waste Manag. 33, 2589-2593 (2013).

36. van Sebille, E. et al. The physical oceanography of the transport of floating marine debris. Environ. Res. Lett. 15, 023003 (2020).

37. Merrell, T. R. Accumulation of plastic litter on beaches of Amchitka Island, Alaska. Mar. Environ. Res. 3, 171-184 (1980).

38. Eriksson, C., Burton, H., Fitch, S., Schulz, M. \& van den Hoff, J. Daily accumulation rates of marine debris on sub-Antarctic island beaches. Mar. Pollut. Bull. 66, 199-208 (2013).

39. Smith, S. D. A. \& Markic, A. Estimates of marine debris accumulation on beaches are strongly affected by the temporal scale of sampling. PLoS ONE 8, 8-13 (2013).

40. Morishige, C., Donohue, M. J., Flint, E., Swenson, C. \& Woolaway, C. Factors affecting marine debris deposition at French Frigate Shoals, Northwestern Hawaiian Islands Marine National Monument, 1990-2006. Mar. Pollut. Bull. 54, 1162-1169 (2007).

41. Frost, A. \& Cullen, M. Marine debris on northern New South Wales beaches (Australia): Sources and the role of beach usage. Mar. Pollut. Bull. 34, 348-352 (1997).

42. Kataoka, T. \& Hinata, H. Evaluation of beach cleanup effects using linear system analysis. Mar. Pollut. Bull. 91, 73-81 (2015).

43. Niaounakis, M. 3-Degradation of plastics in the marine environment. In Plastics Design Library (ed. Niaounakis, M. B. T.-M. of M. P. D.) 127-142 (William Andrew Publishing, Burlington, 2017). https://doi.org/10.1016/B978-0-323-44354-8.00003-3.

44. Corcoran, P. L., Biesinger, M. C. \& Grifi, M. Plastics and beaches: A degrading relationship. Mar. Pollut. Bull. 58, 80-84 (2009).

45. Alkalay, R., Pasternak, G. \& Zask, A. Clean-coast index-A new approach for beach cleanliness assessment. Ocean Coast. Manag. 50, 352-362 (2007).

46. CoNISMa. D4.2.2 Pilot Activities implementation. https://blueislands.interreg-med.eu/fileadmin/user_upload/Sites/Sustainabl e_Tourism/Projects/BLUEISLANDS/D4.2.2_Pilot_Activities_Implementation_CoNISMa.pdf (2020).

47. Ortega-Sánchez, M., Bergillos R. J., López-Ruiz A. \& Losada M. A. Morpho-sedimentary dynamics of mixed sand and gravel coasts. In Morphodynamics of Mediterranean Mixed Sand and Gravel Coasts. SpringerBriefs in Earth Sciences (Springer, Cham). https://doi.org/10.1007/978-3-319-52440-5_5.

48. Pedrotti, M. L. et al. Changes in the floating plastic pollution of the Mediterranean sea in relation to the distance to land. PLoS ONE 11, e0161581 (2016).

49. Ministry of Agriculture, R. D. and E. of C. D5.3.1 Analysis showcasing the direct and indirect economic impact after the implementation of efficient waste management. https://blueislands.interreg-med.eu/results/deliverable-library/ (2020).

50. UNWTO Tourism Trends Snapshot: Tourism in the Mediterranean, 2015 edition. (World Tourism Organization (UNWTO), 2016). https://doi.org/10.18111/9789284416929.

51. Hanke, G. et al. Guidance on Monitoring of Marine Litter in European Seas. Publications Office of the European Union. JRC83985. (2013). https://doi.org/10.2788/99475.

52. Lippiatt, S., Opfer, S. \& Arthur, C. Marine Debris Monitoring and Assessment: Recommendations for Monitoring Debris Trends in the Marine Environment. NOAA Technical Memorandum NOS-ORઐR-46. (2013).

53. Hanke, G. et al. Guidance on Monitoring of Marine Litter in European Seas. https://publications.jrc.ec.europa.eu/repository/handl e/JRC83985 (2013) https://doi.org/10.2788/99816.

\section{Acknowledgements}

The authors would like to acknowledge the BLUEISLANDS project partners who conducted the marine litter monitoring: Council of Mallorca-Environment Department (Mallorca), Taormina Etna Consortium (Sicily), Primorje and Gorski Kotar County (Rab), Wasteserv Malta Ltd (Malta); Region of Crete-Directorate of Environment and Spatial Planning (Crete); Municipality of Mykonos (Mykonos), Rhodes Municipality (Rhodes) 
and Ministry of Agriculture, Rural Development and Environment-Department of Environment of Cyprus (Cyprus); R. Johnson and W. Gray for revising the English and L. Simon Sánchez for her constructive comments.

\section{Author contributions}

M.G. and P.Z. conceived the project. M.G. trained the partners to conduct the surveys. M.G obtained and analyzed data. M.G and P.Z. prepared the manuscript.

\section{Funding}

This research was supported by the Interreg MED project BLUEISLANDS through grant IMED15_3.1_M12_273, by the "María de Maeztu" Programme for Units of Excellence of the Spanish Ministry of Science and Innovation (CEX2019-000940-M) and through MERS (Generalitat de Catalunya), 2017 SGR-1588. This study is a contribution to the i-plastic project (JPI-Oceans-Grant PCI2020-112059).

\section{Competing interests}

The authors declare no competing interests.

\section{Additional information}

Supplementary information is available for this paper at https://doi.org/10.1038/s41598-020-77225-5.

Correspondence and requests for materials should be addressed to M.G.

Reprints and permissions information is available at www.nature.com/reprints.

Publisher's note Springer Nature remains neutral with regard to jurisdictional claims in published maps and institutional affiliations.

(c) (i) Open Access This article is licensed under a Creative Commons Attribution 4.0 International License, which permits use, sharing, adaptation, distribution and reproduction in any medium or format, as long as you give appropriate credit to the original author(s) and the source, provide a link to the Creative Commons licence, and indicate if changes were made. The images or other third party material in this article are included in the article's Creative Commons licence, unless indicated otherwise in a credit line to the material. If material is not included in the article's Creative Commons licence and your intended use is not permitted by statutory regulation or exceeds the permitted use, you will need to obtain permission directly from the copyright holder. To view a copy of this licence, visit http://creativecommons.org/licenses/by/4.0/.

(C) The Author(s) 2020 